\title{
Canadian doctor is new president of MSF International
}

$\mathrm{P}$ ediatric emergency physician and the new president of Médecins Sans Frontières (MSF) International, Dr. Joanne Liu, calls herself a "doctor by day, humanitarian always."

The second Canadian to head the nongovernmental organization, Liu started her career with MSF in 1996, working with Malian refugees in Mauritania. She has since completed more than 20 missions, assisting earthquake victims in Haiti, Somali refugees in Kenya, tsunami survivors in Indonesia and those caught in conflict zones, including the Democratic Republic of Congo and Sudan's Darfur region.

President of MSF-Canada from 2004 to 2009, Liu now sits on the board of directors for MSF-Switzerland and recently launched a telemedicine project to connect field doctors in remote locations to some 300 specialists worldwide.

In addition to her humanitarian commitments, Liu also works as a pediatric emergency physician at the Centre hospitalier universitaire Sainte-Justine in Montréal, Quebec, and at the Health Travel Clinic of the Centre hospitalier de l'Univeristé de Montréal.

Liu joined CMAJ by phone to discuss MSF's coming challenges and her vision of bringing the humanitarian field closer to home.

CMAJ: What attracted you to humanitarian work?

Liu: I wanted to work with MSF since I was a teenager. I read a book about a doctor in Afghanistan ... in the middle of nowhere, trying to do his best. I remember telling myself, "This is what I would like to do one day."

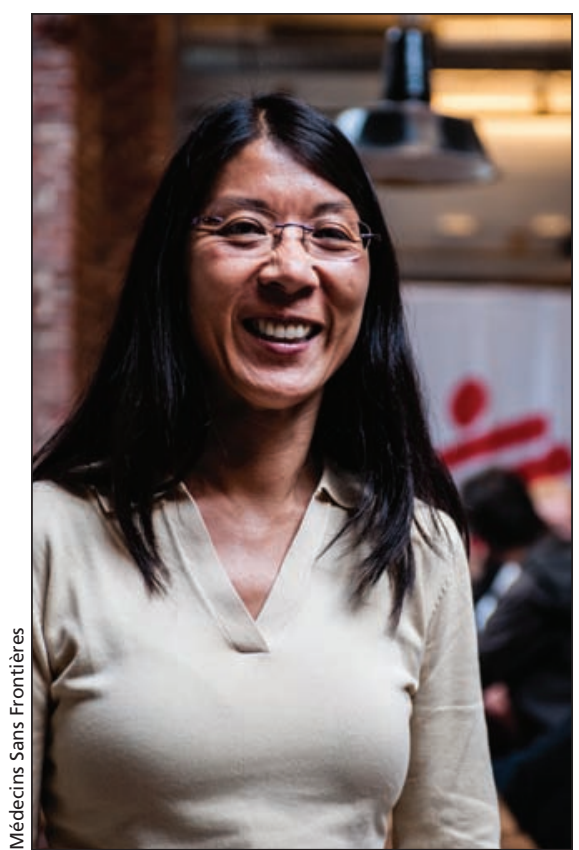

Montréal pediatric emergency physician Dr. Joanne Liu is the second Canadian to take the reins of Médecins Sans Frontières International.

CMAJ: How did that impact your first experience in the field?

Liu: I always laugh when I think about my first mission, because I'd been dreaming and hoping for such a long time -17 years since I read that book - that I was doomed for disappointment. It was primary health care but there were no real emergencies, except possibly difficult deliveries. ... I was waiting for trauma and action.

CMAJ: What are the emerging challenges for MSF?

Liu: Health care structures and staff are being targeted. ... Basically, it's to build a community of concern about the fact that international humanitarian law is not respected in the field. ... There's also the issue of access to vaccines at reasonable prices ... and the big, big coming [challenge] of nontransmittable and chronic disease.

CMAJ: How will your telemedicine experience influence MSF's approach to these issues?

Liu: We need to scale up use of higher tech diagnostic tools, as well as telemedicine. ... I think we're not fully harnessing something that's readily available and not that expensive for the better management of our patients.

CMAJ: You've spoken about putting patients at the center of MSF decision-making - what does that mean to you?

Liu: MSF is going through governance reform and there's a structural growth within MSF that should be seen through the lens of ... "Does this better our response to our patients in the field?" If it doesn't, then we should question it.

CMAJ: How can Canadian physicians get involved?

Liu: I completely understand that going to the field is not for everybody, but it's important that physicians and other Canadians break their indifference to the suffering of people elsewhere. You can contribute by talking about these issues, being aware of what's going on, giving financial support and ... joining in from your office as a telemedicine expert. — Lauren Vogel, CMAJ

CMAJ 2013. DOI:10.1503/cmaj.109-4569 